\title{
A COMPARATIVE STUDY OF THE BRITISH SPECIES OF NUCULA AND NUCULANA
}

\author{
By J. A. Allen \\ Zoology Department, The University, Glasgow, and the Marine Station, Millport
}

(Plate I and Text-figs. I-8)

The survey of the sublittoral fauna of the Clyde Sea Area from 1949 onwards has shown that five species of the Protobranchiata are abundant throughout this region on a variety of substrata. Pelseneer (I89I, I899, I9II), Heath (I937), and Yonge (1939) have contributed much to the knowledge of the group as a whole, but little comparative work has been done at species level. Verrill \& Bush (I897, I898) studied the shell characters of the American Atlantic species. Moore (I93I $a, b)$ worked on the faecal pellets of the British Nuculidae and attempted to distinguish the species by this means, while Winckworth (I930, I93I), mainly in the light of the latter work, attempted to clarify the nomenclature of these species. Winckworth (1932) lists six British species of the family Nuculidae: Nucula sulcata Bronn, N. nucleus (Linné), $N$. hanleyi Winckworth, $N$. turgida Leckenby \& Marshall, $N$. moorei Winckworth and $N$. tenuis (Montagu); and four species of the family Nuculanidae: Nuculana minuta (Müller), Yoldiella lucida (Lovén), Y. tomlini Winckworth and Phaseolus pusillus (Jeffreys). All species of Nucula, except N. hanleyi, were taken from the Clyde Sea Area, although the latter species is included in the Clyde fauna list (Scott Elliot, Laurie \& Murdoch, I90I). Only Nuculana minuta of the Nuculanidae has been taken on the present survey. Yoldiella tomlini is included in the I90I list but is noted as being 'insufficiently attested'. Nucula hanleyi was obtained from the Marine Station, Port Erin, but Yoldiella and Phaseolus were unobtainable.

Difficulty has been experienced in distinguishing the species of Nucula. Recent work (Allen, I953a) shows no differences between $N$. turgida and $N$. moore $i$, these are now combined under the name $N$. turgida Leckenby \& Marshall. Moore (I93I $a$ ) has also suggested that $N$. hanleyi and N. nucleus do not differ from each other, but the present study does not support this view. The specific differences of the British Nuculidae have been investigated and, though no single character is diagnostic, it has been found that the species can be readily distinguished when several characters are considered. An attempt has been made also to correlate specific differences with mode of life. In addition, information on growth rates and length of life has been determined. 
Measurements and observations on Nuculana have been included where they complete the ecological picture and where they indicate similarities at the generic level.

I wish to express my thanks to Prof. C. M. Yonge, F.R.S., for his criticism of the manuscript; and to my wife for her help and criticism. Thanks are due to the Director and Staff of the Millport Marine Station for their help, and to the skipper and crew of the R.V. Calanus for their assistance in obtaining the animals. I also wish to thank Dr N. S. Jones of the Port Erin Marine Station for his kindness in obtaining the sample of Nucula hanleyi without which this work would have been incomplete.

This work was carried out in the first place with financial assistance from the Browne Research Fund of the Royal Society and later by a Research Grant from the Development Commission.

\section{ECOLOGY AND HaBitat}

The animals were taken by means of the Agassiz Trawl and the Naturalist's Dredge. Much of the material was taken in 1949-50 from the samples collected in the course of the Clyde fauna survey. Further large samples were taken in I95I which included Nuculana minuta from the Kilbrennan Sound, Nucula sulcata from the Cumbrae Deep, and $N$. nucleus from the Minard Narrows, Loch Fyne.

The habitat varies for the different species. They occur on all types of substrata ranging from sand to mud and from sandy-gravel to muddy-gravel.

Nucula turgida was obtained from sands and sandy silts in water ranging in depth from 8 to $100 \mathrm{~m}$, and very occasionally from muds at a maximum depth of $180 \mathrm{~m}$. It is most abundant in sandy-mud (Text-fig. I). It is present in large numbers in the Cumbrae Deep where there is a small amount of gravel and sand present in the mud. Where N. turgida is most abundant it is found together with Pectinaria belgica, Cyprina islandica, Abra alba, Corbula (Aloidis) gibba and Amphiura filiformis.

$N$. sulcata was taken in large numbers in floccular muds such as are present in the Arran Deep. It is found also in muds which contain small quantities of gravel and was taken from the Cumbrae Deep; however, there is evidence that animals from this locality differ in some respects from the rest of the Clyde specimens. It was taken in depths ranging from 60 to $200 \mathrm{~m}$. It occurs together with Lipobranchius ieffreysii, Glossus humanus, Amphiura chiajei and Brissopsis lyriformis.

Nucula tenuis is the least common of the British species of Nucula. It is most abundant in soft sandy mud but extends into the less floccular muds and thus overlaps the ranges of both $N$. turgida and $N$. sulcata. It was taken from depths ranging from 20 to $150 \mathrm{~m}$. Associated with it is Thyasira flexuosa and 
some of the species above, e.g. Abra alba, which can tolerate a fairly wide range of particle sizes.

Nucula nucleus was taken in a few restricted areas within the Clyde such as the Fairlie Channel and the Minard Narrows, where the bottom is a coarse muddy gravel. The associated fauna is similarly restricted in habitat, and the dominant species are Astarte sulcata, A. montagui and Dentalium entalis.

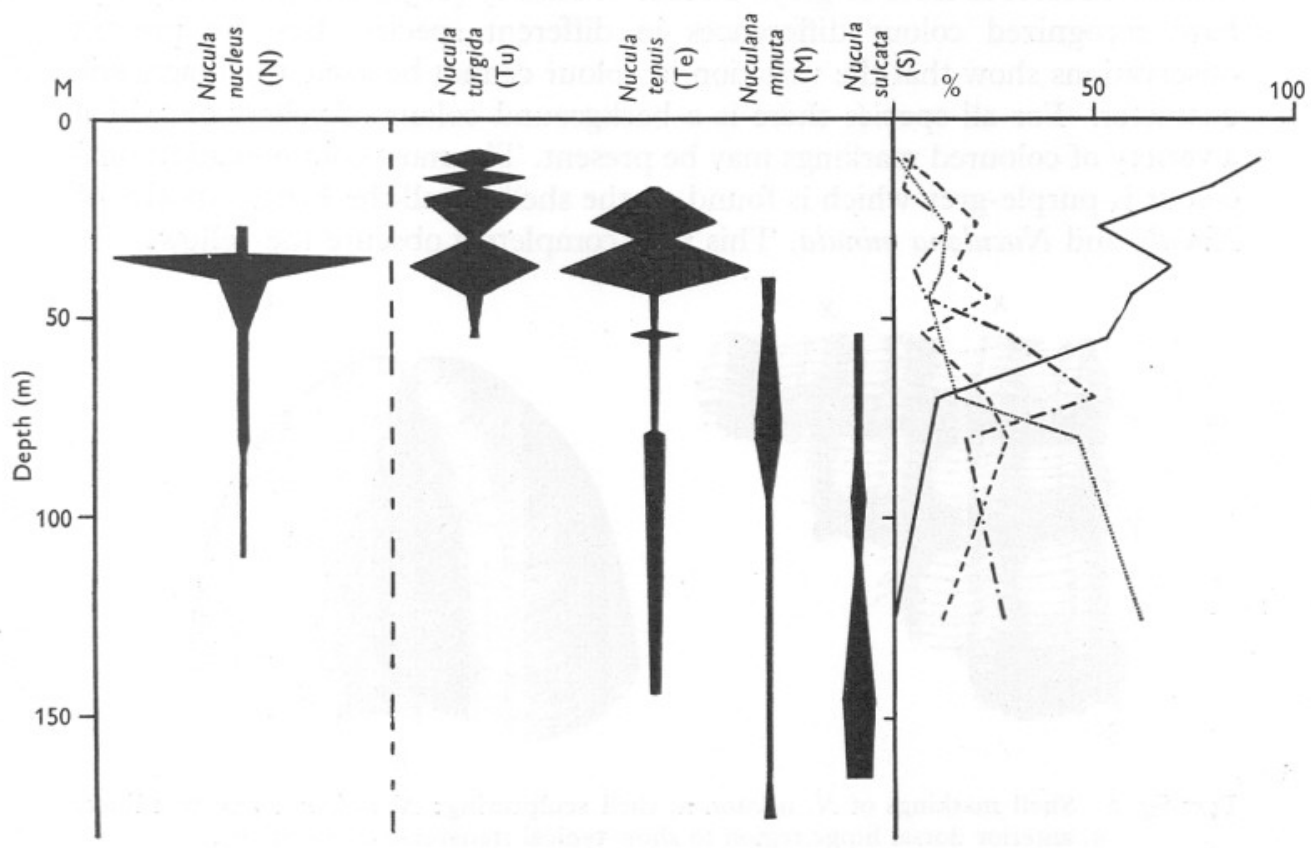

Text-fig. I. Distribution of species of Nucula and Nuculana along a traverse from Etterick Bay, Bute, to the Arran Deep compared with the particle size of the substratum. Particle

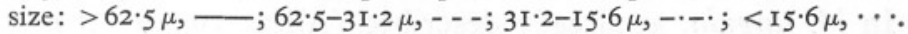

Nucula hanleyi has not yet been taken in the present Clyde survey. It was obtained at Port Erin from a fine sandy gravel at a depth of between I6 and $20 \mathrm{~m}$. It occurs in an offshore fine-gravel community described by Jones (195I).

Nuculana minuta closely resembles Nucula sulcata in its habitat range, although it extends farther into the sandy mud grades and is most abundant in a less floccular mud. The associated fauna is the same as that of N. sulcata.

The faunal survey has shown that over considerable parts of the Clyde area there is a gradation of particle size with depth. Large particles-rocks, stones, sand-at shallow depths grade to floccular muds in the deeps (see Text-fig. I). Correlated with this is a sublittoral zonation of the fauna. This is particularly obvious in the case of the Lamellibranchia. The Nuculidae show 
such a zonation and thus resemble the intertidal Littorinidae. It is where the gradation of the particles is interrupted by shelves and banks of shell gravel that $N$. nucleus is found.

\section{Shell Colour and Characteristics}

Shell colour has been variously described as ranging from yellow through various olivaceous hues to grey. Forbes \& Hanley (I853) and Jeffreys (I863) have recognized colour differences in different species, but the present observations show that the variation in colour cannot be used as a diagnostic character. For all species there is a background colour of yellow on which a variety of coloured markings may be present. The most common additional colour is purple-grey which is found on the shells of all the British species of Nucula and Nuculana minuta. This may completely obscure the yellow.

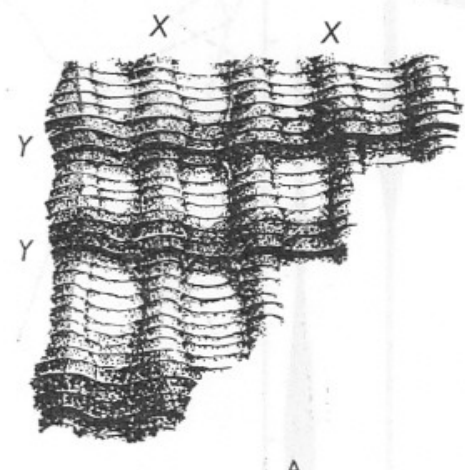

A

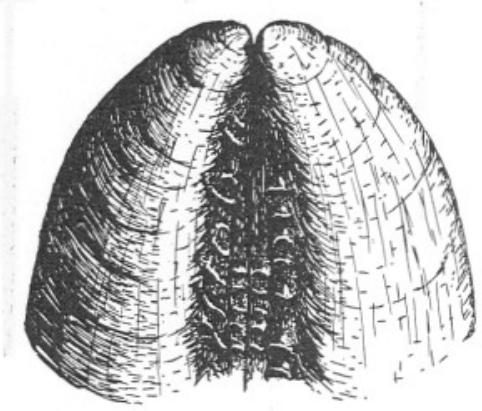

B

Text-fig. 2. Shell markings of $N$. sulcata. A, shell sculpturing: $X$, striae; $Y$, growth lines. $\mathrm{B}$, anterior dorsal hinge region to show typical transverse corrugations.

The grey colour is rarely present in Nucula tenuis, this species usually being clear yellow. In N. turgida, as already described (Allen, I953a), it is often in the form of radiate markings from the umbo to the free-margin (see P1. I). Similar.radiate markings occur on $N$. hanleyi, but these are red and, like those of $N$. turgida, vary in width and numbers. This red colour has been observed also on N. sulcata taken from the Cumbrae Deep, though here it is not as rays but in patches of varying size. Radiate markings have never been observed in $N$. nucleus, $N$. tenuis and Nuculana minuta.

There are differences in the surface of the periostracum, Nucula turgida and $N$. tenuis have a very glossy surface, while $N$. sulcata and $N$. nucleus have matt surfaces. $N$. hanleyi and Nuculana minuta are intermediate in this respect, although the former is more glossy than the latter. The species with matt surfaces collect a deposit of manganese on their shells while those with a glossy surface do not. Nuculana and Nucula hanleyi are again intermediate, the deposit never being so heavy. 
There are few differences in shell sculpturing. N. nucleus, $N$. hanleyi and $N$. turgida have striae radiating from the umbo to the free-margin which may be very slightly decussated by an occasional strongly marked growth line. The growth lines of the latter three species are obvious and the inside edge of the free-margin is crenated. N. sulcata is finely decussated (Text-fig. 2A) and in the hinge area anterior to the umbo there are characteristic irregular transverse corrugations (Text-fig. 2B). The inside edge of the free-margin is also crenated. $N$. tenuis and Nuculana minuta have no radiating striae. The former shell has a smooth surface with very few growth lines showing while the latter is strongly ridged with growth lines, neither have a crenated inner shell margin.

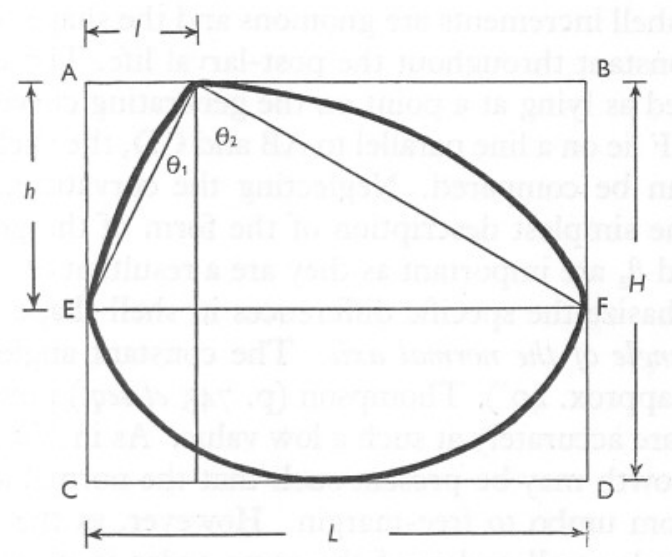

Text-fig. 3. Diagram to show shell measurements taken. For explanation of symbols see text.

\section{Shell MEASURements}

Apart from ridges on the gut wall which produce grooved faecal pellets (Moore, I93I $a$ ), examination of the anatomy did not show any significant differences between the species studied. Comparisons, therefore, have been made from shell features. Measurements were taken of $4 \mathrm{I}_{3}$ Nuculana minuta, 490 Nucula sulcata, 227 N. nucleus, 2500 N. turgida (large numbers taken for examination of the validity of $N$. moorei, see Allen, I953a), I00 $N$. hanleyi and ro6 $N$. tenuis.

Shells were placed on a grid ABCD (see Text-fig. 3) so that a line joining the points $\mathrm{E}$ and $\mathrm{F}$ is parallel to $\mathrm{AB}$ and $\mathrm{CD}$ (point $\mathrm{F}$ in Nuculana was taken as the dorsal corner of the posterior end of the shell). The distances $H, L, l$ and $h$ were then measured, and from these the angles $\theta_{1}$ and $\theta_{2}$ were calculated. In addition, the greatest width $(W)$ was measured. All measurements were recorded to the nearest $\mathrm{O} \cdot \mathrm{I} \mathrm{mm}$ and the angles to the nearest minute. Measurements were taken with the aid of a travelling microscope and vernier calipers. 
The mathematical description of the growth and form of the molluscan shell has been discussed by Huxley (I932), Thompson (I942), Lison (1949), and Owen (1953). Quantitative measurement of the specific differences of the British Nuculidae has been considered in relation to the above work and with reference to: (i) growth and form of the generating curve, (ii) the constant angle of the normal axis, (iii) the form of the normal axis, and (iv) the angle of retardation.

Growth and form of the generating curve. ${ }^{1}$ Although Owen states that the measurements of 'length', 'height' and 'breadth' do not alone provide a satisfactory means of comparing shell form in different species, they nevertheless provide useful information. In the majority of lamellibranchs, including Nucula, shell increments are gnomons and the shape of the generating curve remains constant throughout the post-larval life. The umbo of Nucula may be considered as lying at a point on the generating curve and, providing the points $\mathrm{E}$ and $\mathrm{F}$ lie on a line parallel to $\mathrm{AB}$ and $\mathrm{CD}$, the shell measurements $L, H, l$ and $h$ can be compared. Neglecting the curvature, these measurements provide the simplest description of the form of the generating curve. The angles $\theta_{1}$ and $\theta_{2}$ are important as they are a resultant of $l$ and $L-l$ and $h$ and further emphasize the specific differences in shell shape.

The constant angle of the normal axis. The constant angle of the lamellibranch is small (approx. $40^{\circ}$ ). Thompson (p. 743 et seq.) points out that it is not easy to measure accurately at such a low value. As in Nucula, a tangential component of growth may be present such that the normal axis is no longer a straight line from umbo to free-margin. However, as the tangential component in Nucula is small and is of the same order in all species, the ratio $H / \frac{1}{2} W$ has been used to compare the concavity of the valves, i.e. the constant angle.

The form of the normal axis. This is turbinate for all Nucula species. The measurement of the degree of turbination is difficult and no accurate determination was made. Observation of $N$. turgida and $N$. hanleyi with radial shell markings and of those species with striae indicates that the degree of turbination is of the same order in all.

Angle of retardation. As the umbo approximates to a point on the generating curve in all the Protobranchiata, the angle of retardation, i.e. the retardation of growth of the inner as compared with the outer whorl, approaches infinity and thus can be neglected.

In addition, age and growth rates and hinge teeth numbers are compared in the species studied.

\section{Generating curve}

\section{COMPARISON OF SHELl SHAPES}

Comparison of the overall measurements of height $(H)$ and length $(L)$ shows there is very little difference between the five species of Nucula. Thus

1 The nomenclature proposed by Owen (1952, 1953) has been used. 
mean shell heights calculated for a length of I cm are as follows (length was chosen because the growth increments in length are almost constant for the British species of Nucula): N. nucleus $0.83 \mathrm{~cm}, N$. sulcata (Cumbrae Deep) $0.8 \mathrm{I} \mathrm{cm}, N$. hanleyi $0.80 \mathrm{~cm}, N$. turgida $0.78 \mathrm{~cm}, N$. sulcata (Arran Deep) $0.78 \mathrm{~cm}$ and $N$. tenuis $0.76 \mathrm{~cm}$. Comparisons of the individual variations in the overall measurements of height and length emphasize the fact that the measurements overlap each other too much to show any significant difference between the species. However at high values the measurements of $N$. nucleus

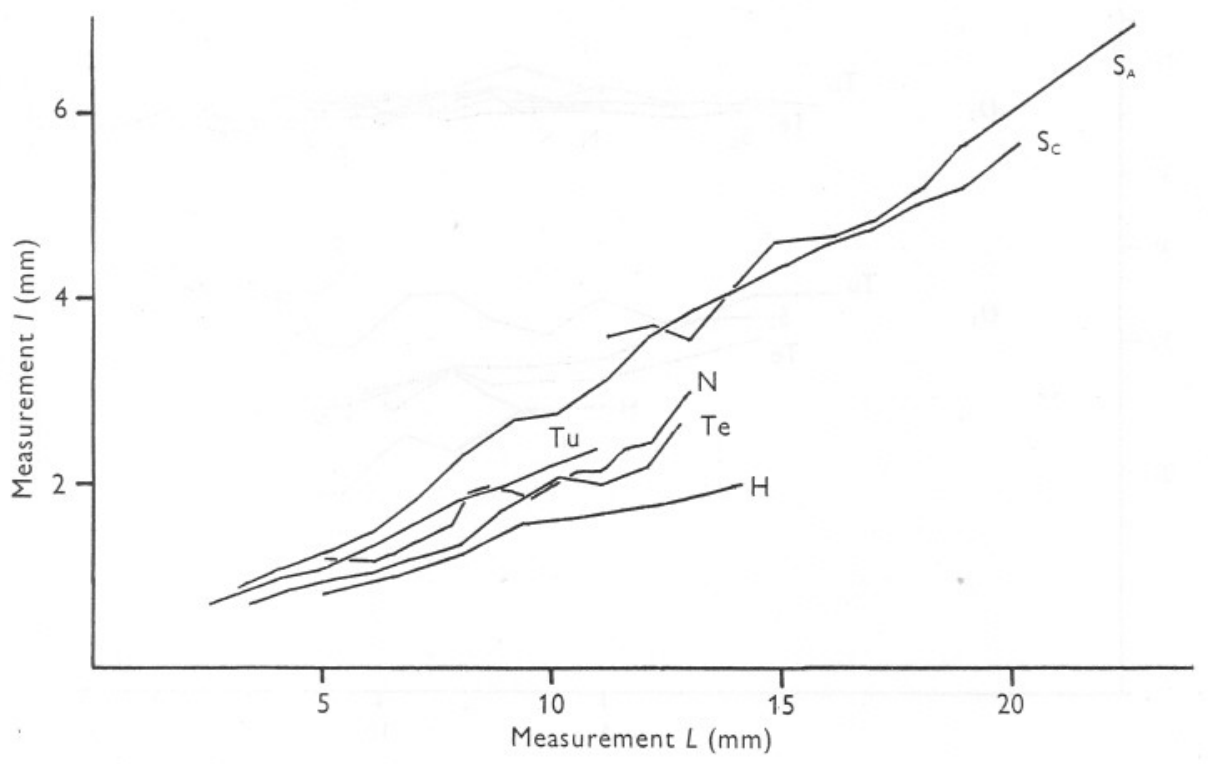

Text-fig. 4. Comparison of the mean shell measurements, $l$, plotted against length $(L)$. $\mathrm{H}$, Nucula hanleyi; N, N. nucleus; S, N. sulcata; Tu, N. turgida; Te, N. tenuis; A, Arran Deep; c, Cumbrae Deep.

and $N$. tenuis (the highest and lowest respectively in relative height measurements) when considered by themselves are nearly distinct. There is also a distinction between $N$. sulcata from the Cumbrae Deep and the Arran Deep. This is also indicated in other measurements, and the possible explanation will be discussed later (see p. 465).

Although the overall measurements show few differences the angles $\theta_{1}$ and $\theta_{2}$ need not be the same for all species. Reference to Text-fig. 4 shows that specific differences for the value $l$ are marked and that $N$. hanleyi has the lowest value for $l$ and $N$. sulcata the highest. Here, the measurements of $N$. nucleus and $N$. tenuis lie much closer together, the latter having the lower values for $l$. These slight differences in $l$ and $H$ (N. tenuis having a lower value for both measurements) make the values of $\theta_{1}$ for both these species approxi- 
mately equal, while the values for $\theta_{2}$ are distinct. This explains why $N$. tenuis appears elongate when compared with the other species (Text-fig. 5).

$\theta_{1}$ and $\theta_{2}$ are the best measurements for comparing the generating curves as they take into account both measurements for height and length. Values of $\theta_{1}$ in Text-fig. 5 further show that $N$. sulcata and $N$. hanleyi are distinct while values for the other species are nearly identical. Although differences in $L-l$ will not be so clearly reflected in $\theta_{2}$ when this is in the region

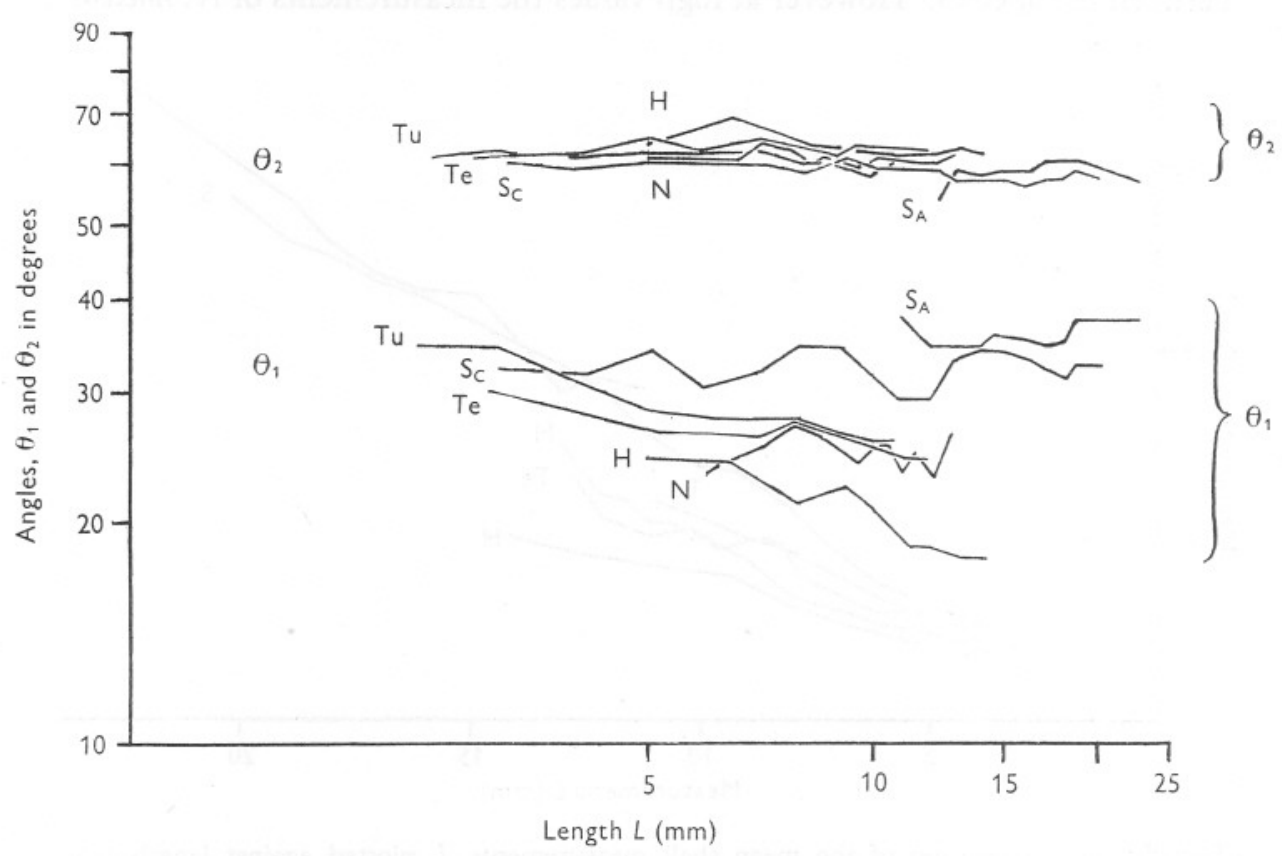

Text-fig. 5. Comparison of the mean shell angles $\theta_{1}$ and $\theta_{2}$, double-log plot. Abbreviations as given under Text-fig. 4.

of $60^{\circ}$, Text-fig. 5 shows that values of $\theta_{2}$ for $N$. nucleus approximate to those of $N$. sulcata while those of $N$. tenuis lie close to those of $N$. hanleyi. Again there are differences in the measurements of $N$. sulcata from the Cumbrae Deep and those from the Arran Deep. Whereas the species other than $N$. sulcata with low values for $\theta_{1}$ have high values for $\theta_{2}, N$. sulcata from the Arran Deep with a larger angle $\theta_{1}$ than $N$. sulcata from the Cumbrae Deep, also has a larger angle $\theta_{2}$ than the shells from the Cumbrae Deep.

\section{Constant Angle}

Reference to Table I shows that the differences in the constant angle are very slight. However, they do bear out the field observations that $N$. nucleus has the greatest spiral angle and $N$. tenuis the smallest. 


\section{Discussion and Conclusions on Shell Shape}

It is convenient at this stage to summarize the above data and attempt to correlate the differences in shell measurements with the differences in habitat. Table I summarizes the shell measurements of the species of Nucula which are calculated for a shell length of $\mathrm{I} \cdot 0 \mathrm{~cm}$. Although there are few differences in the overall shell measurements, the species can be distinguished by considering the measurements in relation to the position of the umbo. Studies on normal variation show that there is an overlap of the measurements, but consideration of all the measurements, particularly when these are taken in

Table I. Mean Shell Measurements Calculated for $L=\mathrm{I} \cdot \mathrm{O} \mathrm{CM}$

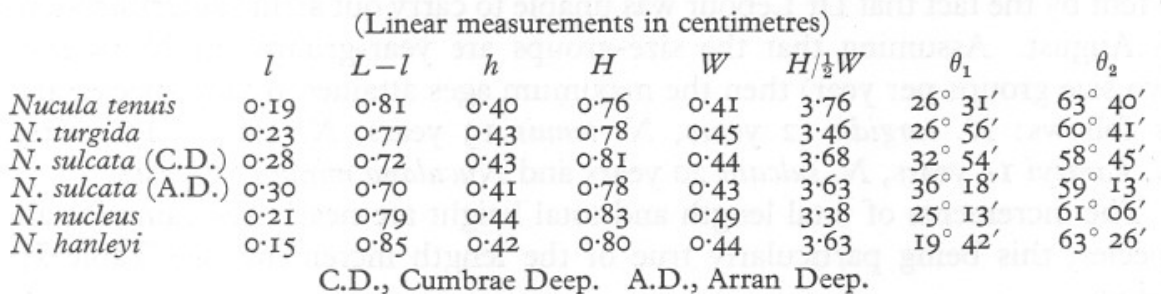

conjunction with other characters (see p. 47I), show that the species of Nucula can be distinguished from each other. The most important shell measurements are the angles $\theta_{1}$ and $\theta_{2}$ for they are the resultant of $l$ and $L-l$ and any slight difference in height. The effect of the slightly smaller height measurements of $N$. tenuis has meant that while $\theta_{1}$ for this shell is of the same order as that of $N$. turgida, its value for $\theta_{2}$ is slightly larger than that of $N$. hanleyi. This explains the characteristically elongate appearance of $N$. tenuis. $N$. turgida and $N$. nucleus are the only species that cannot be readily separated by shell measurements, although $N$. nucleus has the highest measurement of height and the greatest spiral angle. N. sulcata shows differences in measurements at different localities. Similar differences have been shown for Chlamys septemradiata taken from different regions of the Clyde (Allen, I953 $b$ ). Differences between Nucula sulcata from different localities and the shell differences between the other species are apparently correlated with differences in their habitat. N. sulcata living in soft floccular mud has a large measurement for $l$, while $N$. hanleyi in firm sandy-gravel has a small measurement for $l$. The other species of Nucula are intermediate both in type of substratum and measurement $l$. The mud of the Cumbrae Deep is more compact than that of the Arran Deep and has a small amount of sand and gravel mixed with it. Thus some differences might be expected between $N$. sulcata taken from these localities. Thus differences in shell shape may have arisen because those with a small $l$ value may be better adapted for movement in firm substrata. 


\section{AGE AND GROWTH}

The histograms in Text-fig. 6 show that the species of the Protobranchiata examined have definite size-groups which are in all probability year-groups (see Allen, I953a). N. turgida and N. sulcata were found to have ripe sperm and eggs in January and February but no successful fertilizations were carried out. N. nucleus differs from the other species in that the size-groups indicate that it either grows at half the rate of other Nucula species or that there are two breeding periods annually. Lebour (1938) states that the breeding period is from spring to autumn (April to November). This is longer than the other species. There are probably two maxima, a view that is supported to some extent by the fact that Dr Lebour was unable to carry out artificial fertilization in August. Assuming that the size-groups are year-groups (in $N$. nucleus two size groups per year) then the maximum ages attained by the species are as follows: $N$. turgida I2 years, $N$. tenuis I3 years, $N$. nucleus I3 years, $N$. hanleyi 14 years, $N$. sulcata 20 years and Nuculana minuta 17 years.

The increments of total length and total height are nearly the same for all species, this being particularly true of the length increment (see Table II below).

\begin{tabular}{|c|c|c|c|c|}
\hline \multicolumn{5}{|c|}{ (Measurements in $\mathrm{mm}$ ) } \\
\hline & $L$ & $l$ & $L-l$ & $h$ \\
\hline $\begin{array}{l}\text { Nucula turgida } \\
\text { N. temuis }\end{array}$ & $\begin{array}{l}0.94 \\
0.96\end{array}$ & $\begin{array}{l}0.19 \\
0.18\end{array}$ & $\begin{array}{l}0.75 \\
0.78\end{array}$ & $\begin{array}{l}0.43 \\
0.42\end{array}$ \\
\hline N. hanleyi & I.OI & 0.13 & 0.82 & 0.47 \\
\hline N. sulcata (C.D.) & 0.96 & 0.27 & 0.69 & 0.40 \\
\hline N. sulcata (A.D.) & 0.96 & 0.28 & 0.68 & 0.38 \\
\hline N. nucleus & 0.94 & 0.21 & 0.73 & $0.4 \mathrm{I}$ \\
\hline Nuculana minuta & 0.98 & 0.52 & 0.46 & 0.28 \\
\hline
\end{tabular}

Nucula hanleyi is an exception but this is offset by a correspondingly high growth rate in height. N. nucleus, the other species living in gravel, also has a high height increment while $N$. sulcata from the floccular mud of the Arran Deep has the lowest. The growth rate remains practically constant throughout the life of the species. Nuculana minuta, although being a member of a different family with marked differences in shell shape, has the same growth increment of length with similar year-groups (see Text-fig. 6).

Shell weights have been compared and these show that the curves for increase of shell weight with length are similar (Text-fig. 7). Nucula hanleyi differs slightly in that the initial rate is slightly less than $N$. turgida and $N$. nucleus. This increases between 8 and $10 \mathrm{~cm}$ length so that at high

EXPLANATION OF PLATE I

Lateral views of the right valve of the five British species of Nucula. I, N. sulcata (Cumbrae Deep); 2, N. sulcata (Arran Deep); 3, N. nucleus; 4, N. turgida; 5, N. hanleyi; 6, N. tenuis. 

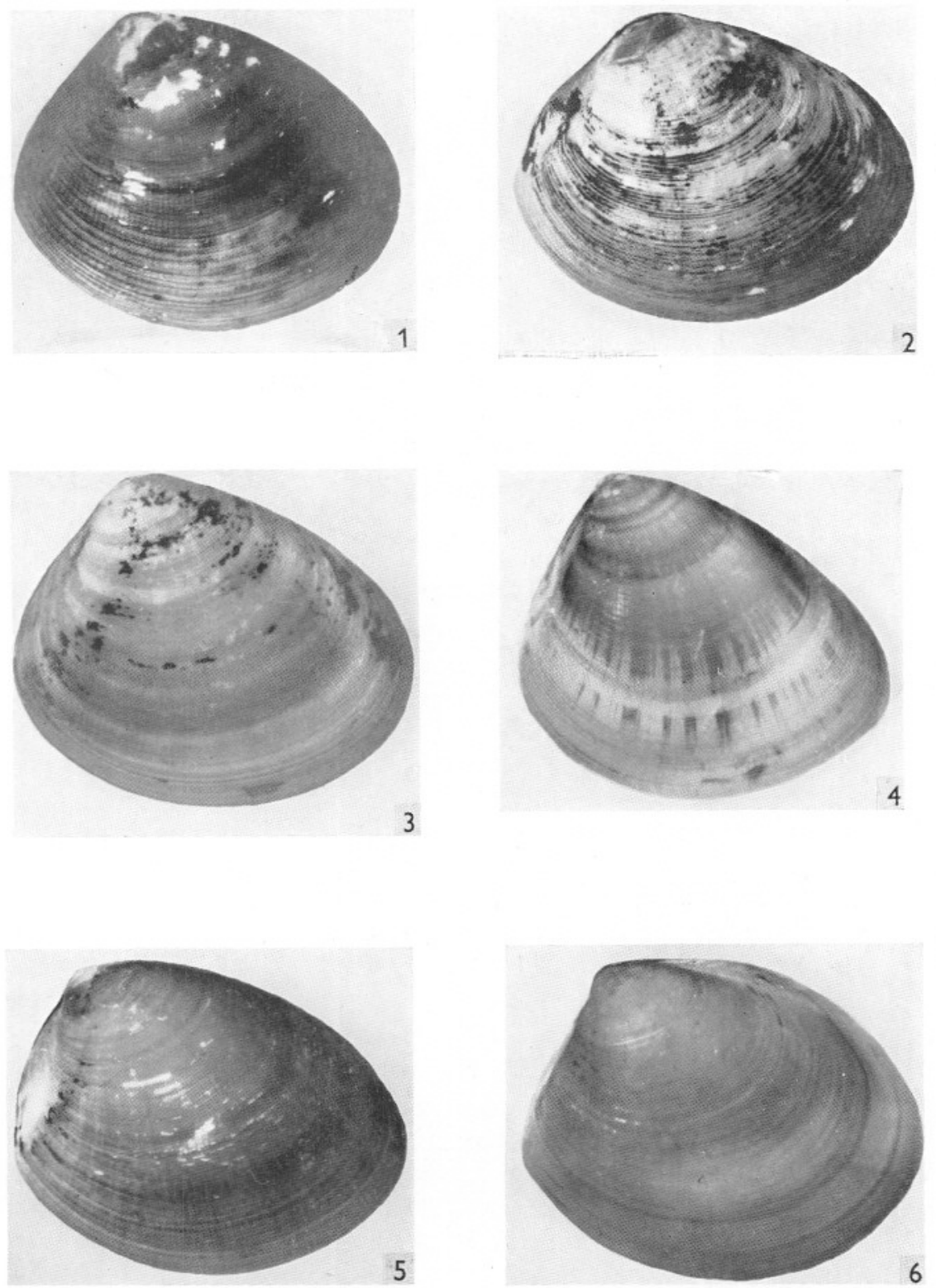


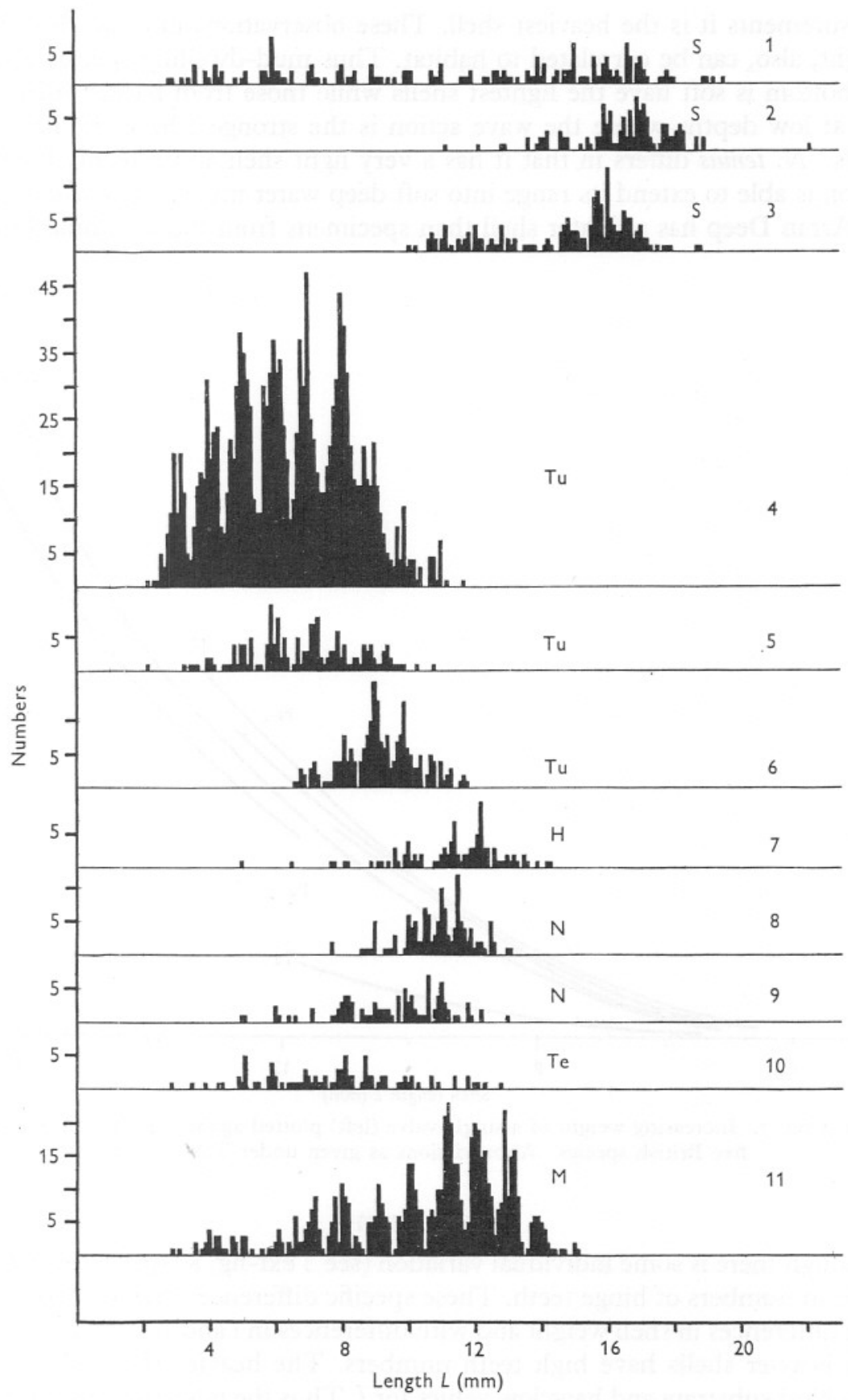

Text-fig. 6. Population histograms of the largest samples taken. I, Nucula sulcata, Cumbrae Deep, July I95I. 2, N. sulcata, Arran Deep, July I95I. 3, N. sulcata, Arran Deep, Aug. I95I. 4, N. turgida, Cumbrae Deep, Oct. I950. 5, N.turgida, Cumbrae Deep, June I95I. 6, N. turgida, Minard Narrows, July I95I. 7, N. hanleyi, Port Erin, Jan. I952. 8, N. nucleus, Fairlie Channel, Dec. 1948. 9, N. nucleus, Minard Narrows, Aug. I95 I. I0, N. tenuis, Etterick Bay, July I949. II, Nuculana minuta, Kilbrennan Sound, Aug. I95I. 
measurements it is the heaviest shell. These observations indicate that shell weight, also, can be correlated to habitat. Thus mud-dwelling species where the bottom is soft have the lightest shells while those from harder substrata and at low depths where the wave action is the strongest have the heaviest shells. N. tenuis differs in that it has a very light shell and possibly for this reason is able to extend its range into soft deep water muds. $N$. sulcata from the Arran Deep has a lighter shell than specimens from the Cumbrae Deep.

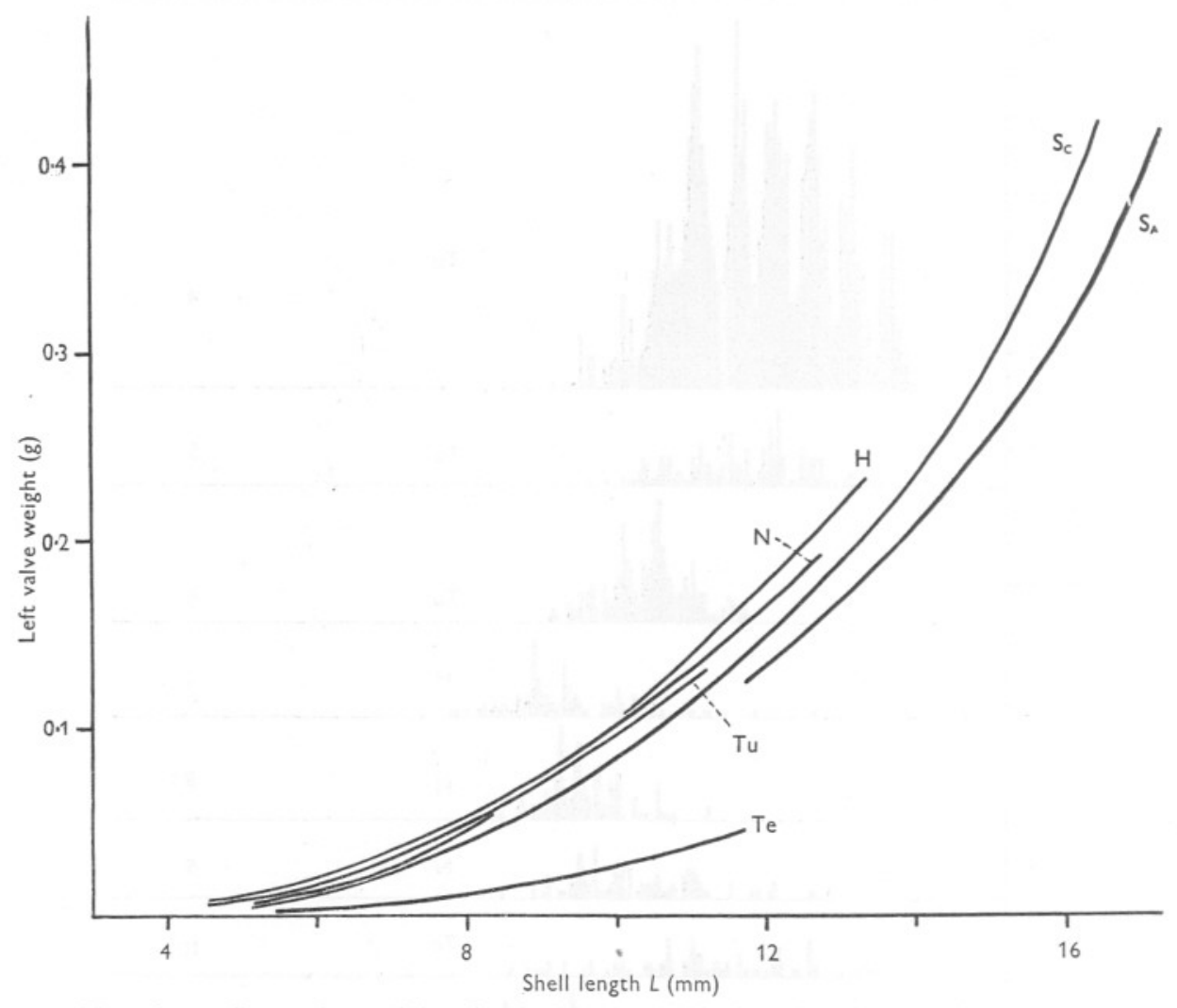

Text-fig. 7. Increasing weight of a single valve (left) plotted against length $(L)$ in the five British species. Abbreviations as given under Text-fig. 4 .

\section{Hinge TeETh}

Although there is some individual variation (see Text-fig. 8) species of Nucula differ in numbers of hinge teeth. These specific differences may be correlated with differences in shell weight and with differences in $l$ and $L-l$. The species with heavier shells have high teeth numbers. The heavier shells also come from hard substrata and have low values for $l$. Thus the posterior hinge region is shorter than in the species from soft substrata and the numbers of teeth in 
this region will be restricted by lack of space. Specific differences in the length of the relatively long anterior hinge are not great enough to have much effect on teeth numbers. Shell weight rather than limiting space has the greater effect on teeth numbers (see Text-fig. 8). N. sulcata with the longest value of $l$ has low numbers of teeth and it is only in the case of $N$. hanleyi that a low value for $l$ appreciably lowers the number of posterior teeth. $N$. tenuis with the very fragile thin shell has the least number of teeth.

Hinge numbers increase with increasing age and there are specific differences in the rate at which they are laid down. This rate is not the same anterior and posterior to the hinge, the posterior teeth being laid down at a slower rate. N. sulcata from the Arran and Cumbrae Deeps are almost identical in teeth numbers, with a slight tendency for fewer in the Arran Deep shells.

\section{Table III. Average increase in Shell Length (MM) For Each ADDITIONAL TOOTH}

$\begin{array}{lcc} & \text { Anterior } & \text { Posterior } \\ \text { Nucula sulcata } & \mathrm{I} \cdot 20 & \mathrm{I} \cdot 65 \\ \text { N. tenuis } & \mathrm{I} \cdot \mathrm{I} 5 & \mathrm{I} \cdot 40 \\ \text { N. turgida } & 0.85 & 0.95 \\ \text { N. nucleus } & 0.60 & 0.95 \\ \text { N. hanleyi } & 0 \cdot 70 & \mathrm{I} \cdot \mathrm{I} 5\end{array}$

\section{Discussion AND CoNCLusions}

The British species of Nucula occur commonly on a variety of sublittoral substrata. They are so similar that it has been found difficult to distinguish between them. N. turgida and $N$. moorei have recently been shown to be the same species (Allen, I953 $a$ ) while Moore (I93 I $a$ ) has suggested that N. hanleyi and N. nucleus are identical. Careful examination shows that five British species can be recognized.

Species of the Protobranchiata have successfully invaded most sublittoral substrata, the main exception being rocky bottoms. Each species is restricted to a particular type of substratum. Within the Clyde, where, over much of the area there is a gradation of particle sizes with depth, they show a sublittoral zonation.

Shell colour is similar in all species. N. turgida and $N$. hanleyi may have coloured rays from the umbo to the free-margin varying in width and extent. There is little shell sculpturing, that of $N$. sulcata being the most pronounced. $N$. tenuis differs from the other species in that it has no crenations along the inner edge of the free-margin of the shell. There are differences in the degree of gloss of the surface of the periostracum ranging from $N$. tenuis with a high gloss to $N$. sulcata with a matt surface.

Shell measurements were taken and studied in the light of recent work on the growth and form of the lamellibranch shell. There is little difference in the overall shell measurements of length and height but the measurements 


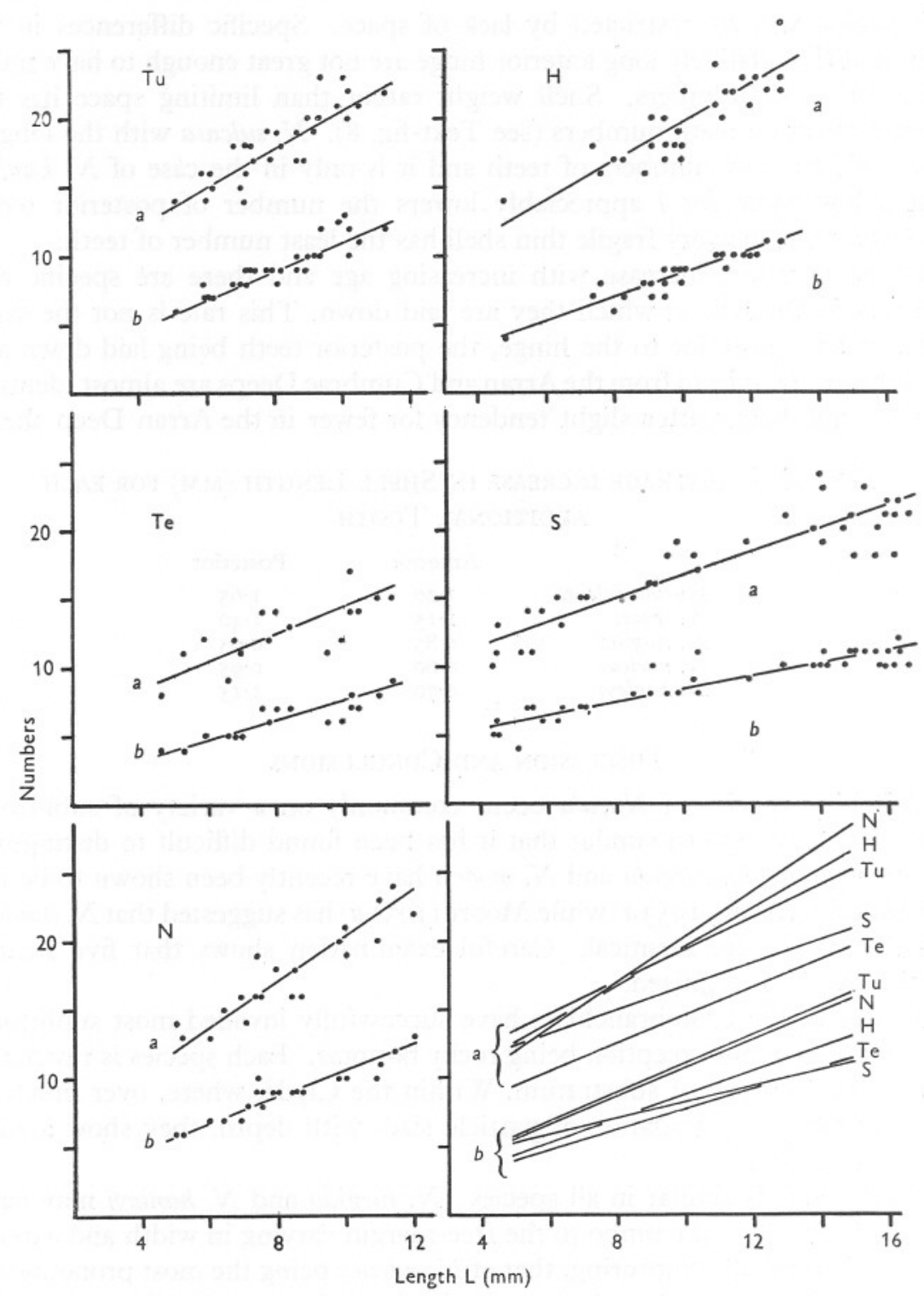

Text-fig. 8. The variation and comparison of the numbers of anterior $(a)$ and posterior $(b)$ teeth at different values of length $(L)$. Abbreviations as given under Text-fig. 4.

$l$ and $L-l$ are important in distinguishing between the species. The angles $\theta_{1}$ and $\theta_{2}$ are also important as they are the result of both differences in $l$ and $L-l$ and height. Thus the slightly lower measurements in height of $N$. tenuis and $N$. sulcata from the Arran Deep are reflected in the angles $\theta_{1}$ and $\theta_{2}$ and 
emphasize differences already shown in $l$ and $L-l$. Differences in shell form may be correlated with differences in habitat. Thus species in hard substrata with large particles $\left(N\right.$. hanleyi) have smaller measurements for $\theta_{1}$ and $l$ than those from soft mud ( $N$. sulcata). This may be correlated with the fact that a greater pull of the foot is necessary for movement through the harder ground. It has been shown that the weight of shell in the species living in mud is less than in species living in sand and gravel. This is reflected in the number of shell teeth present, i.e. fewer in species from mud. This is probably associated with the fact that shells from sand and gravel tend to be more robust, particularly in the Clyde Sea Area where they are in shallow water and will be affected more by wave action.

Not only can specific differences be related to differences in substratum but species themselves can differ in different habitats. This is very well shown in N. sulcata.

$N$. nucleus and $N$. hanleyi are not one and the same species as was suggested by Moore in his study on faecal pellets. On the other hand, N. turgida and $N$. moorei, recently shown to be the same species, were separated by Winckworth on supposed differences in the faecal pellets as demonstrated by Moore. It must be concluded that differences in pellets cannot be used by themselves for the identification of Nucula species.

The specific differences have been summarized in Table IV.

Table IV. Comparison of the Species of NuCUla

\begin{tabular}{|c|c|c|c|c|c|}
\hline & N. hanleyi & N. nucleus & N. turgida & N. tenuis & $N$. sulcata \\
\hline Habitat & Sandy gravel & Muddy gravel & Muddy sand & $\begin{array}{l}\text { Sandy mud to } \\
\text { mud }\end{array}$ & Mud \\
\hline $\begin{array}{l}\text { Shell colour, } \\
\text { etc. }\end{array}$ & $\begin{array}{l}\text { Red rays, perio- } \\
\text { stracum fairly } \\
\text { glossy, inner } \\
\text { margin } \\
\text { crenated }\end{array}$ & $\begin{array}{l}\text { No rays, perio- } \\
\text { stracum matt, } \\
\text { inner margin } \\
\text { crenated }\end{array}$ & $\begin{array}{l}\text { Purple-grey } \\
\text { rays some- } \\
\text { times present, } \\
\text { periostracum } \\
\text { glossy, inner } \\
\text { margin } \\
\text { crenated }\end{array}$ & $\begin{array}{l}\text { No rays, perio- } \\
\text { stracum glossy, } \\
\text { inner margin } \\
\text { not crenated }\end{array}$ & $\begin{array}{l}\text { No rays, perio- } \\
\text { stracum matt, } \\
\text { inner margin } \\
\text { crenated, slightly } \\
\text { decussated with } \\
\text { irregular trans- } \\
\text { verse corrugations } \\
\text { above ant. hinge }\end{array}$ \\
\hline $\begin{array}{l}\text { Shell shape, } \\
\text { measurements, } \\
\text { in parentheses } \\
\text { in mm, mean } \\
\text { values given }\end{array}$ & $\begin{array}{l}\text { Lowest measure- } \\
\text { ment for } l(0.15) \\
\text { and } \theta_{1}\left(19^{\circ} 42^{\prime}\right)\end{array}$ & $\begin{array}{l}\text { Differs only } \\
\text { slightly from } \\
N \text {. turgida but } \\
\text { has highest } \\
\text { measurement } \\
\text { of } H(0.83) \\
\text { and constant } \\
\text { angle }(3.38)\end{array}$ & $\begin{array}{l}\text { All measure- } \\
\text { ments are } \\
\text { intermediate } \\
\text { to other } \\
\text { species }\end{array}$ & $\begin{array}{l}\text { Lowest measure- } \\
\text { ment of } H(0 \cdot 76) \\
\text { and largest angle } \\
\theta_{2}\left(63^{\circ} 40^{\prime}\right)\end{array}$ & $\begin{array}{l}\text { Highest measure- } \\
\text { ment for } l(0.30) \\
\text { and } \theta_{1}\left(36^{\circ} 18^{\prime}\right)\end{array}$ \\
\hline $\begin{array}{l}\text { Maximum age, } \\
\text { growth, etc. }\end{array}$ & $\begin{array}{l}\text { I4 years, greatest } \\
\text { growth rate and } \\
\text { heaviest at } \\
\text { lengths above } \\
\text { I cm. One breeding } \\
\text { period/year }\end{array}$ & $\begin{array}{l}\text { I3 years, two } \\
\text { breeding } \\
\text { periods/year }\end{array}$ & $\begin{array}{l}\text { I2 years, one } \\
\text { breeding } \\
\text { period/year }\end{array}$ & $\begin{array}{l}\text { I3 years, very } \\
\text { light and fragile } \\
\text { shell with very } \\
\text { low hinge teeth } \\
\text { numbers, one } \\
\text { breeding period/ } \\
\text { year }\end{array}$ & $\begin{array}{l}20 \text { years, one } \\
\text { breeding period/ } \\
\text { year }\end{array}$ \\
\hline
\end{tabular}




\section{REFERENCES}

Allen, J. A., I953a. Observations on Nucula turgida Leckenby and N. moorei Winckworth. F. Mar. biol. Ass. U.K., Vol. 31, pp. 515-28.

- $1953 b$. Observations on the epifauna of the deep water muds of the Clyde Sea Area, with special reference to Chlamys septemradiata (Müller). F. Anim. Ecol., Vol. 22, pp. 240-60.

Forbes, E. \& Hanley, S., I853. A History of the British Marine Mollusca, and their Shells, Vol. II. London.

Heath, H., I937. The anatomy of some protobranch mollusks. Mém. Mus. Hist. nat. Belg., T. 2, fasc. IO, pp. I-26.

Huxley, J. S., 1932. Problems of Relative Growth. London.

Jefrereys, J. G., I863. British Conchology, Vol. II. London.

Jones, N. S., I95I. The bottom fauna off the south of the Isle of Man. F. Anim. Ecol., Vol. 20, pp. 132-44.

Lebour, M. V., I938. Notes on the breeding of some lamellibranchs from Plymouth and their larvae. F. Mar. biol. Ass. U.K., Vol. 23, pp. II9-44.

Lison, L., I949. Recherches sur la forme et la méchanique de développement des coquilles des lamellibranches. Mém. Inst. Sci. nat. Belg., I949 (2), Fasc. 34, pp. I-87.

Moore, H. B., I93I $a$. The systematic value of a study of Mollusca faeces. Proc. malacol. Soc. Lond., Vol. I9, pp. 28I-90.

— I93 $b$. The specific identification of faecal pellets. F. Mar. biol. Ass. U.K., Vol. 17, pp. 359-65.

Owen, G., 1952. Shell form in the Lamellibranchia. Nature, Lond., Vol. I70, pp. $148-9$.

— 1953. The shell of the Lamellibranchia. Quart. F. micr. Sci., Vol. 94, pp. $57-70$.

Pelseneer, P., r89r. Contribution à l'étude des lamellibranches. Arch. Biol., Paris, T. II, pp. I47-3I2.

— 1899. Recherches morphologiques et phylogénétiques sur les mollusques archaiques. Mém. Acad. R. Belg., T. 57, pp. I-I I2.

- I9Ir. Les lamellibranches de l'expédition du Siboga. Partie anatomique. Siboga Exped., Vol. 53 a, pp. I-I25.

Scott Elliot, G. F., LaURIE, M. \& MURdoch, J. B., I90I. Fauna, Flora and Geology of the Clyde Area. Glasgow.

Thompson, D'Arcy W., I942. On Growth and Form. Cambridge University Press.

VerRILL, A. E. \& BUSH, H. J., I897. Revision of the genera of Ledidae and Nuculidae of the Atlantic coast of the United States. Amer. F. Sci., Vol. 3, pp. 51-63.

_ I 1898. Revision of the deep-water Mollusca of the Atlantic coast of North America, with descriptions of new genera and species. Part I. Bivalvia. Proc. U.S. nat. Mus., Vol. 20, pp. 775-90I.

Winckworth, R., 1930. Notes on nomenclature. Proc. malacol. Soc. Lond., Vol. 29, pp. I4-I5.

— I93I. On Nucula nitida Sowerby. Proc. malacol. Soc. Lond., Vol. 29, pp. 280-I. I932. The British marine Mollusca. F. Conch., Vol. I9, pp. 2 I I-52.

Yonge, C. M., I939. The protobranchiate Mollusca; a functional interpretation of their structure and evolution. Phil. Trans. B, Vol. 230, pp. 79-I47. 